\title{
Natural Dyes: Extraction and Applications
}

\author{
Lizamoni Chungkrang*, Smita Bhuyan and Ava Rani Phukan \\ Department of Textiles and Apparel Designing, College of Community Science, Assam \\ Agricultural University, Jorhat, Assam, India \\ *Corresponding author
}

\section{A B S T R A C T}

\section{Keywords}

Coloration, Dyeing, Extraction, Mordant, Natural dye etc.

\section{Article Info}

Accepted:

12 December 2020

Available Online: 10 January 2021
Natural dyes are obtained from natural sources such as vegetable, animal or mineral matters. These dyes are generally used in coloration of textiles, food, cosmetics and drugs. This article attempts to reviews the classification of natural dyes according to the method of application available natural dye sources, mordant and its classification, different mordanting methods, extraction methods, dyeing methods and advantages and disadvantages of natural dyes have been discussed.

\section{Introduction}

Presently there is a great demand for the use of natural colours throughout the world due to non-biodegradable and carcinogenic nature associated with synthetic dyes (Chungkrang and Bhuyan, 2020). They are not produce any undesired by-products and at the same time they help in regenerating the environment, therefore natural dyes are the safe dyes (Akkewar, 1999; Darwekar et al., 1999). Government of Germany was the first to take initiative to put ban on azo-dyes for manufacturing, dyeing and importing textiles and other consumer goods dyed with these dyes from January 1, 1995 by the act of
German Legislation (Consumer Goods Ordinance). Netherlands followed a ban with effect from August 1, 1996 on similar lines. European Union is likely to impose ban on these toxic dyes shortly. India has also banned the use of specific azo-dyes and under notification "sufficient legal teeth" had been given for taking panel action against those who use these dyes (Kapoor and Pushpangadan, 2001; Singh et al., 2006).

Natural dyes are important since they are better than synthetic dyes in many ways. Undeniably, the natural dyes are healthier products, purely because they do not comprise chemicals damaging to fitness (Baliarsingh et 
al., 2013). These dyes are collected from nature and no need to apply manufacturing process to prepare them. These dyes are easily decomposed in nature after using and they do not pollute the environment while destroying them after end use (Alam et al., (2020). The natural dyes are used mainly in coloration of textiles, food, drugs and cosmetics. Small quantities of dyes are also used in coloration of paper, leather, shoe polish, wood, cane, candles and such other products requiring coloration (Gulrajani, 2001).

\section{Classification of natural dyes according to the method of application}

The natural dyes can be classified into three groups according to the method of application (Gulrajani and Gupta, 1992; Dedhia, 1998; Samanta and Konar, 2012; Jihad, 2014).

\section{Direct or substantive dyes}

A dye, soluble in water can be taken up directly by the material to be dyed without any pretreatment, is known as direct or substantive dye. These dyes can be applied directly in a hot aqueous dye solution without the use of fixing agent or mordant. These dyes are mainly used for cellulosic fibers, protein fibers and polyamides. Examples of direct natural dyes are turmeric, annatto, berberry, safflower etc. The direct dyes are further classified into acid dyes and basic dyes.

Acid dyes: These dyes are used for wool and silk and are applied in the acidic medium. They have the structure of either sulphonic or carboxylic group.

Basic dyes: These dyes on ionization give coloured action, which form electrovalent bonds with the carboxylic acid groups of wool and silk. These dyes are applied in neutral to mildly acidic $\mathrm{pH}$.
Mordant dyes: Mordant dyes are those dyes, which have affinity for the mordanted fibres. Most of the natural dyes yield different shades of colours with different mordants. The mordant dyes are classified as monogenetic and polygenetic. Monogenetic dye produce only one colour according to the mordant present on the fiber or applied along with the dye materials. Polygenetic dye produces different colours according to the mordant employed.

Vat dyes: The vat dyes derive the name from the fermented wooden called 'vat' which was used at one time for reducing the dye and converting it into soluble form. The process of the solubilization of the dye is called as 'vatting'. The soluble form of the dye is called as leuco dye. The leuco form of the dye is not only soluble in water but also has an affinity for the natural fibers. The dye colour is pale yellow but the true colour is produced only on treatment with hot soap solution. They include the most ancient of dyes such as indigo and tyrian purple etc.

Disperse dyes: Natural dye has not been classified as disperse dye, however by looking at the structure and solubility characteristics of the natural dyes it is felt that some of the natural dyes can be classified as disperse dyes. Disperse dye has a low relative molecular mass, low solubility to the dye molecule. These dyes have hydroxyl and amino groups which imparts some solubility to the dye molecule. One such dye could be Lawsone. Many other flavones and anthraquinone dyes can qualify to be classified as disperse dyes.

Mordant and its classification: Nearly all natural dyes require mordants to give substantativity. The term mordant has been derived from the Latin word mordeo, which means "to bite" or to "take hold of (Gohl and Vilensky, 1983). The majority of natural dyes 
need a chemical in the form of metal salts to create on affinity between the fiber and the pigment. These chemicals are known as mordants (Bisht and Goel, 1999; Singh and Srivastava, 2015; Vankar et al., 2009).

\section{Classification}

Three type's mordants are used in dyeing textiles materials, metallic mordants, tannin and tannic acid and oil mordants (Agarwal and Patel, 2000).

Metal Salts or Metallic Mordants: Several different metal salts can be used for mordanting such as Alum (Potassium aluminum sulphate), Copper (Copper sulphate), Chrome (Potassium dichromate), Iron (Ferrous sulphate) and Tin (Stannous chloride, Stannic chloride)

Tannins and Tannic acid: Tannin and Tannic acid is present in the barks, leaves, fruits and galls of many plants. The word 'tannin' comes from the early French word Tan, which means bark of an oak. The term tannin was introduced by Sequin in the year 1976 to indicate various plants extracts which have capacity to convert hides and skins into leather. Tannins are classified into two categories:

(i) Condensed or flavonoid (Catechol type) tannins based on polymeric flavor, obtained from acacia catechu. Tannins such as tannic acid, harda etc are considered as natural mordants.

(ii) Hydrolysable (Pyrogallot type) tannins based on esters of gallic acid, obtained from myrobalan fruit, oak bark, gallnuts, pomegranate rind etc.

In the same plant different parts like bark, nut, leaf and wood may contain different types of tannins (Dwivedi, 1993).
Oil or Oil Mordants: Oil -mordants are mainly used in the dyeing of Turkey red colour from madder. The main function of the oil-mordant is to form a complex with alum used as the main mordant. Since alum is soluble in water and does not have affinity for cotton, it is easily washed out from the treated fabric. The naturally occurring oils contain fatty acids such as palmitic, stearic, oleic, ricinolic etc. and their glycerides. The $\mathrm{COOH}$ groups of fatty acids react with metal salts and get converted into-COOM, where $\mathrm{M}$ denotes the metal, for instance in the case of alum it would be Al. subsequently, it was found that the treatment of oils with concentrated sulphuric acid produces sulphonated oils which possess better metal binding capacity than the natural oils due to the introduction of sulphonic acid group, $\mathrm{SO} 3 \mathrm{H}$. The sulphonic acid can react with metal salts to produce $-\mathrm{SO} 3 \mathrm{M}$. The bound metal can then form a complex with the mordant dye such as madder to give Turkey red colour of superior fastness and hue.

\section{Mordanting Methods}

Mordanting is classified on the basis of application time of mordants (Gohl and Villensky, 1983). These are pre-mordanting (before dyeing), simultaneous mordanting and post mordanting (after dyeing).

Pre-mordanting: In this method, the textile material is first immersed into the mordant solution for 30 to 60 minutes at the room temperature or higher temperature with a liquor ratio of $1: 5$ to $1: 20$. Then dyed the textile material treated with mordant. After dyeing, the dyed material is wash.

Simultaneous mordanting: For this method, the textile material, mordant and dye are immersed in a dyebath simultaneously. For the optimization of dyeing conditions, dyeing process variables can be studied for the 
specific fibre-mordant-natural dye system in order to improve the colour yield of textiles. After dyeing, the textile material is wash properly.

Post-mordanting: In this method, the dyeing process is carried out on the textile material without mordant. After dyeing, the dyed fabric is treated in another bath containing the mordant solution. Treatment condition may vary depending on the type of fibre, dye and mordant system being used. After dyeing, wash the textile material properly.

\section{Extraction methods of natural dyes}

Extraction of colour materials from natural resources is a complicated process. They need specific technique to extract dye from their original sources. The different techniques for extraction of natural colourants are as follows:

Aqueous extraction: In this method, if the raw material is in dry form, broken into small pieces or powdered by grinding and soaked in wate to loosen the cell structure. If the raw material is in wet form then it is chopped into fine pieces or grinded to fine paste. Then boiled and is filtered to remove the noncolouring matters from the dye liquor. Both can be used easily to impart colour in different things.

There are some disadvantages associated with aqueous extraction method like time consuming for extracting colour, high temperature requirement, required large volume of water, heat sensitive colouring substances gets reduced at high temperature low dye yield, only water soluble colouring components can be extracted etc.

Acidic or alkaline extraction: Extraction of dye is done under acidic or alkaline medium. For this dilute acidic or alkaline can also be used which helps in hydrolysis of glycosides resulting in better extraction. Acidic method is used in extraction of tesu natural dye from tesu flower. Alkaline medium is used for those colour extraction which contain phenolic groups. Extraction of colour from lac insect, annatto seeds, safflower petals are extracted by this method.

Ultrasonic microwave extraction: In this extraction method, raw material is treated in aqueous solution using microwave or ultrasonic rays, so that the high temperature, less time and faster rate of extraction can be done. Colour from butterfly pea and annatto seeds are extracted by using this method.

By fermentation: In this extraction method, micro-organisms present raw materials are used to carry out the fermentation and thus help the extracting metod. Colour from turmeric, indigo, annatto seeds extracted by using this method. Time consuming, bad smell due to microbial action, immediate extraction of colour after harvesting are some disadvantages of this method

Enzymatic Extraction: Commercially available enzymes including cellulase, amylase, and pectinase have been used to loosen the binding material present in natural materials like bark, roots or any hard part of plant.

Solvent extraction: Organic solvents like acetone, petroleum, ether, chloroform and ethanol are used in the extraction of natural dyes. Solvent extraction method is more efficient than aqueous method. The yield of dye is good quality, required low temperature and the quantity of water requirement is also less.

Supercritical Fluid Extraction: In this extraction method, a fluid having physical properties between gas and fluid is used. It 
has low surface tension, low viscosity and good diffusivity properties which results better interaction with the substrate.

\section{Dyeing methods}

\section{Conventional Dyeing System}

Textile dyeing started in past carried out conventionally. Textile materials were directly processed with the dye bath at high temperatures. Coloration method for textiles using chemically formed gels with considerable freedom for making color designs and precise pattern prints, and can be used with conventional dyeing and printing equipment was developed. With the time, dyeing also matured with the development of optimization of dyeing parameters, and in recent times advanced technologies evolved like plasma treatment and enzymatic processing etc. (Bohrn and Moggio, 1980).

\section{Advanced Dyeing Systems}

Advanced technologies or methods are trending in dyeing in recent times owing to their improved results over the conventional dyeing. Plasma treatment and ultrasonic dyeing methods are technically advanced and sustainability compatible methods used in technologically evolved textile industry. Improved results in ultrasound-assisted dyeing are generally attributed to cavitations phenomena and other mechanical effects are produced such as dispersion (breaking up of aggregates with high relative molecular mass), degassing (expulsion of dissolved or entrapped air from fiber capillaries), diffusion (accelerating the rate of diffusion of dye inside the fiber) and intense agitation of the liquid.

The acceleration in dyeing rates observed by many workers might be the cumulative effects of all these factors (Vajnhandl and Marechal, 2005).

\section{Advantages and disadvantages of natural dyes}

\section{Advantages of natural dyes}

Usually biodegradable and renewable also Non-toxic, non-allergic and non-carcinogenic as these are obtained from animals or vegetable matters without any chemical processing

Easy to extract and purify

No disposal problems with natural dye waste Colours produced by natural dyes are usually soft, lustrous and soothing to the eyes

\section{Disadvantages of natural dyes}

Non-standardized colour recipes and methods Requires skilled workmanship and therefore natural dyes are costly

Applicable to natural fibres only (cotton, wool, silk and linen)

Inadequate fastness properties

Some of the mordants are harmful

\section{Application of natural dyes}

Natural dyes are generally applied in industries such as textile, food, leather (Sivakumar et al., 2011), cosmetics (Yusuf et al., 2017), pharmaceutical (Chigurupati et al., 2002) etc.

According to the literature, natural dyes such as Walnut shells (Mirjalili and Karimi, 2013), Onion shells (MIAH et al., 2016; Nurunnesa et al., 2018), Cassia singueana (Teklemedhin et al., 2018) Curcuma longa L. (Ibrahim et al., 2010), Senegalia catechu (Ansari et al., 2018), Butea monosperma (Daberao et al., 2016), Hibiscus Rosa Sinensis (Bose and Nag, 2012), Ziziphus jujuba Mill. (Chungkrang et al., 2018), Orange \& Lemon peels (Kumar and Dhinakaran, 2017), Quercus infectoria Oliv. (Shahid et al., 2012), Saraca asoca and Albizia lebbeck (Baliarsingh et al., 2012) and 
so forth produce natural pigments are used in textile dyeing industries.

In addition to their biodegradability and compatibility with the environment, natural dyes have been recently discovered to exhibit other functional properties such as antimicrobial activity (Khan et al., 2012; Shahid et al., 2013), anti-fungal, anti-viral activity (Gupta et al., 2004), insect repellent (Kato et al., 2004; Ali et al., 2013), UV protection (Sun and Tang, 2011; Hou et al., 2013) and deodorizing agents (Lee et al., 2009), dye-sensitized solar cells (Zhou et al., 2011; Narayan,2012).

Varieties of natural pigments like safflower (Cho et al., 2000), turmeric, quinines (Yusuf et al., 2017), anthocyanins (Wrolstad, 2004), betalains (Azeredo, 2009), chlorophylls (Humphrey, 2004), carotenoids (Mortensen, 2006), tannins (Khanbabaee, 2001) etc. are used in coloration of foods. They have different groups of chemical compounds which may be used directly as colorants or in chemically modified form to produce different hues ranging from green through yellow, orange, red, blue, and violet, depending on the source of colorant or increased stability.

The cosmetic industry now employs many natural dyes due to the fact they will cause fewer side affect than the employment of synthetic dyestuffs but they can also provide extra properties such as UV protection, skin moisturizing and anti-aging (Chengaiah et al., 2010). Natural pigments obtained from natural resources with active functional components have shown high biological activities and exhibited different properties depending on each kind of pigments which make them excellent colouring materials for natural cosmetics and functional health foods (Yusuf et al., 2017).
In conclusion due to the non-biodegradable and carcinogenic nature associated with the synthetic dyes, people started using natural colours. Textile industry is the main field for application of natural dyes but it can also be used in other fields such as foods, cosmetics, drugs, paper printing etc. There are many research works that has been carried out by many researchers/scientists belonging to industry, small and medium entrepreneurs, social organizations (NGO's), Government organizations, researchers in various educational institutes and research organizations etc. on the revival of natural dyes, but more researches are required to standardize the methods for its application.

\section{References}

Agarwal, B.J. and Patel, B.H. (2000). The reincarnation of natural colourants - A review. Chemical Weekly. 16(5): 139146.

Akkewar, D.M. (1999). National colour of commercial importance. Convention on Natural Dyes. 9-11th December, Department of Textiles Technology, IIT, Delhi. pp. 132.

Alam, S.M.M., Islam, S. and Akter, S. (2020). Reviewing the Sustainability of Natural Dyes. Advance Research in Textile Engineering, 5(2): $01-06$.

Ali, M.A.; Almahy, H.A. and Band, A.A.A. (2013). Extraction of carotenoids as natural dyes from the Daucus carota Linn (carrot) using ultrasound in Kingdom of Saudi Arabia. Research Journal of Chemical Sciences, 31: 6366.

Ansari, T. N.; Iqbal, S. and Barhanpurkar, S. (2018). Ecofriendly Dyeing with Senegalia catechu Using Biomordant. International Journal of Creative Research Thoughts, 6(1): 1351-1354.

Azeredo, H. (2009). Betalains: properties, sources, applications, and stability-a 
review. Int. J. Food Sci. Technol., 44(12): 2365-2376.

Baliarsingh, S.; Jena, J.; Das, T and Das, N.B. (2013). Role of cationic and anionic surfactants in textile dyeing with natural dyes extracted from waste plant materials and their potential antimicrobial properties. Industrial Crops and Products, 50: 618-624.

Baliarsingh, S.; Panda, A.K.; Jena, J.; Das, T. and Das, N.B. (2012). Exploring sustainable technique on natural dye extraction from native plants for textile: identification of colourants, colourimetric analysis of dyed yarns and their antimicrobial evaluation. Journal of Cleaner Production, 37: 257-264.

Bisht, B.G. and Goel, A. (1999). Dyeing of natural fibre - Bhimal with natural dye. Kilmora. Tex. Trends 42(5): 33-35.

Bohrn, W.J. and Moggio, W.A. (1980). Coloration method for textiles. U.S. Patent No. US4, 222,740 A.

Bose, S. and Nag, S. (2012). Isolation of Natural Dyes from the Flower of Hibiscus Rosa-Sinensis. American Journal of Pharm Tech Research, 2(3): 761-770.

Chengaiah, B.; Rao, K.M.; Kumar, K.M.; Alagusundaram, M. and Chetty, C.M. (2010). Medicinal importance of natural dyesa review. International Journal of Pharm Tech Research, 2(1):144-154.

Chigurupati, N.; Saiki, L.; Gayser, C. and Dash, A.K., (2002). Evaluation of red cabbage dye as a potential natural color for pharmaceutical use. Int.J. Pharmaceut., 241(2): 293-299.

Cho, M.H.; Paik, Y.S. and Hahn, T.R. (2000). Enzymatic conversion of precarthamin to carthamin by a purified enzyme from the yellow petals of safflower. J. Agric. Food Chem., 48(9): 3917-21.

Chungkrang, L.; Phukan, A.R. and Kalita, B.(2018). Eco-dyeing of wool yarn with
Ziziphus jujuba Mill. (Ber) and its colour fastness properties. Journal of Applied and Natural Science, 10 (3): 1046 -1052.

Chungkrang, L. and Bhuyan, S. (2020). Natural Dye Sources and its Applications in Textiles: A Brief Review. Int. J. Curr. Microbiol. App. Sci, 9(10): XX-Xx.

Daberao, A. M.; Kolte, P. P. and Turukmane, R. N. (2016). Cotton Dying with Natural Dye. International Journal of Research and Scientific Innovation, 3(8): 157-161.

Darwekar, M.; Gorpade, B. and Vankar, P.S. (1999). Microwave assisted improved synthesis of indigoid dyes and anthaquinoid dyes, indigo, yellow 3G, tyrian blue, alizarin, orange and alizarin blue. Convention on Natural Dyes. 911th December, Department of Textiles Technology, IIT, Delhi. pp. 132.

Dedhia, E.M. (1998). Natural dyes. Colourage, 16(3): 45.

Dwivedi, A.P. (1993). The non-wood resources. International Book Distributors, Dehradun. pp. 213-214.

Gohl, E.P.G. and Vilensky, L.D. (1983). Textile Science - An explanation of fibre properties. CBS publisher and distribution. New Delhi. pp. 68.

Gupta, D.; Khare, S.K. and Laha, A. (2004). Antimicrobial properties of natural dyes against Gram-negative bacteria. Coloration Technology, 120 (4): 167171.

Gulrajani, M.L. (2001). Technology for production and application of natural dyes on textiles. In conventional proceedings natural dyes. Department of Textile Technology, December 1718, IIT, Delhi. pp. 3-9.

Gulrajani, M.L. and Gupta, D. (1992). Natural dye and their application to textiles. Department of Textile Technology, Indian Institute of Technology, New 
Delhi.

Humphrey, A.M. (2004). Chlorophyll as a color and functional ingredient. J, Food Sci., 69(5).

Hou, X.; Chen, X.; Cheng, Y.; Xu, H.; Chen, L. and Yang, Y. (2013). Dyeing and UV-protection properties of water extracts from orange peel. J. Clean. Prod., 52, 410-419.

Ibrahim, N.A.; El-Gamal, A.R.; Gouda, M. and Mahrous, F. (2010). A new approach for natural dyeing and functional finishing of cotton cellulose. Carbohydrate Polymers, 82(4): 12051211.

Jihad, R. (2014). Dyeing of Silk Using Natural Dyes Extracted From Local Plants. International Journal of Scientific \& Engineering Research, 5 (11): 809-818.

Kapoor, V.P. and Pushpangadan, P. (2001). Use of natural dyes in preparation of Herbal-Gulals. In conventional proceedings natural dyes. Department of Textile Technology, December 1718, IIT, Delhi. pp. 17-19.

Kato, H.; Hata, T. and Tsukada, M. (2004). Potentialities of natural dyestuffs as antifeedants against varied carpet beetle, Anthrenus verbasci. J. Japan Agric. Res. Quart., 38(4): 241-251.

Khan, S.A.; Ahmad, A.; Khan, M.I.; Yusuf, M.; Shahid, M.; Manzoor, N. and Mohammad, F. (2012). Antimicrobial activity of wool yarn dyed with Rheum emodi L. (Indian Rhubarb). Dyes and Pigments, 95: 206-214.

Khanbabaee, K. and Van, Ree, T. (2001). Tannins: classification and definition. Nat. Prod. Rep., 18(6): 641-649.

Kumar, C. S. S. and Dhinakaran, M. (2017). Extraction and Application of Natural Dyes from Orange Peel and Lemon Peel on Cotton Fabrics. International Research Journal of Engineering and Technology, 4(5): 237-238.
Lee, Y.; Hwang, E. and Kim, H. (2009). Colorimetic assay and antibacterial activity of cotton, silk and wool fabrics dyed with peony, pomegranate, clove, Coptis chinenis and gallnut extracts. Materials, 2: 10-21.

MIAH, M.R.; Telegin, F.Y. and Rahman, M.R. (2016). Eco-friendly dyeing of Wool fabric using natural dye extracted from onion's outer shell by using water and organic solvents. International Research Journal of Engineering and Technology (IRJET), 03 (09): 451-467.

Mirjalili, M. and Karimi, L. (2013). Extraction and Characterization of Natural Dye from Green Walnut Shells and Its Use in Dyeing Polyamide: Focus on Antibacterial Properties. Journal of Chemistry, pp. 1-9.

Mortensen, A. (2006). Carotenoids and other pigments as natural colorants. Pure Appl. Chem., 78(8): 1477-1491.

Narayan, M.R. (2012). Dye sensitized solar cells based on natural photosensitizers. Renew. Sust. Energy Rev., 16(1), 208215.

Nurunnesa; Hossain, M. A. and Rahman, M. M. (2018). Extraction of Natural Dye Collected from Outer Skin of Onion and its Application on Silk Fabric. Global Journal of Researches in Engineering: $J$ General Engineering, 18(3).

Samanta, A.K. and Konar, A. (2012). Technical Handbook on Natural Dye and Colouration, Dept. of Jute and Fibre Tech, IJT, Calcutta University, Kolkata 45-72.

Shahid, M.; Ahmad, A. and Yusuf, M. (2012). Dyeing, fastness and antimicrobial properties of woolen yarns dyed with gallnut (Quercus infectoria Oliv.) extracts. Dyes and Pigments, 95(1): 5361. Shahid, M.;

Singh R. and Srivastava, S. (2015). Exploration of Flower Based Natural Dyes - A Review. Research Journal of 
Recent Sciences, 4(IVC-2015): 6-8.

Shahid, M.; Shahid-ul-Islam and Mohammad, F. (2013). Recent advancements in natural dye applications: a review. Journal of Cleaner Production, 53: 310- 331.

Singh, O.P.; Bains, S. and Goraya, G. (2006). Dyeing of wool with Arjun (Arjuna terninella) dye. Tex. Trends XLVIX (6): 29-31.

Sivakumar, V.; Vijaeeswarri, J. and Anna, J.L. (2011). Effective natural dye extraction from different plant materials using ultrasound. Ind. Crops Prod., 33(1): 116-22.

Sun, S.S. and Tang, R.C. (2011). Apsorption and UV protection properties of the extract from honeysuckle onto wool. Industrial \& Engineering Chemistry Research, 50: 4217-4224.

Teklemedhin, T. B. and Gopalakrishnan, L. H. (2018). Environmental Friendly
Dyeing of Silk Fabric with Natural Dye Extracted from Cassia singueana Plant. Journal of Textile Science and Engineering, S3: 2-6.

Vankar, P.S. (2000). Chemistry of natural dyes. Resonance, 5(10); 73-80.

Vajnhandl, S. and Le Marechal, A.M. (2005). Dyes and Pigments, 65(2): 89-101.

Wrolstad, R.E. (2004). Anthocyanin pigments-Bioactivity and coloring properties. J. Food Sci., 69(5), C419C425.

Yusuf, M.; Shabbir, M. and Mohammad, F. (2017). Natural colorants: Historical, Processing and Sustainable Prospects. Nat. Prod. Bioprospect., 7(1), 123-145.

Zhou, H.; Wu, L.; Gao, Y. and Ma, T. (2011). Dye-sensitized solar cells using 20 natural dyes as sensitizers. $J$. Photochem. Photobiol. A: Chem., 219(2):188-194.

\section{How to cite this article:}

Lizamoni Chungkrang, Smita Bhuyan and Ava Rani Phukan. 2021. Natural Dyes: Extraction and Applications. Int.J.Curr.Microbiol.App.Sci. 10(01): 1669-1677.

doi: https://doi.org/10.20546/ijcmas.2021.1001.195 